\title{
LAS EMOCIONES EN EL EJERCICIO PRÁCTICO DE LA DOCENCIA
}

\section{The emotions in the teaching practice}

\section{Les émotions dans l'exercice de l'énseignement}

\section{José M. Esteve ZaraZAGA}

Departamento de Teoría e Historia de la Educación. Facultad de Ciencias de la Educación. Campus de Teatinos. Universidad de Málaga. 29071 Málaga. Correo-e: esteve@uma.es

Fecha de recepción: enero de 2006

Fecha de aceptación definitiva: abril de 2006

BIBLID [(1130-3743) 18, 2006, 85-107]

RESUMEN

El artículo defiende la idea de que los docentes son el elemento central sobre el que gira la construcción del clima emocional del aula; ya que son ellos quienes generan el sistema de trabajo, el tipo de relaciones humanas y los códigos básicos de interacción y comunicación en el aula. Entre las claves para estudiar el clima emocional del aula se estudia el papel que los profesores juegan a partir de su propia identidad profesional, y los mensajes emocionales que envían a los alumnos a través de los canales de comunicación que utilizan, sobre todo en la comunicación no verbal. Éstos son los elementos básicos sobre los que se construye la empatía.

Palabras clave: clima emocional del aula, papel de los profesores, identidad profesional. 
SUMMARY

This article defends the idea that teachers are the central element of pivot in the construction of the emotional climate of the classroom; because they are who generate the system of work, the kind of human relations and the basic codes of communication and interaction in the classroom. Between the keys for the study of the emotional climate of the classroom the role of the teachers is studied from there own professional identity and the emotional messages they send to students through the channels of communication they use, particularly through the non verbal communication. Those are the basic elements for the construction of empathy.

Key words: emotional climate of the classroom, role of the teachers, professional identity.

SOMMAIRE

Cet article défend l'idée que les enseignants sont l'élément central dans la construction du climat émotionnel de la classe; en tant qu'ils sont l'axe du system de travail, du type des relations humaines et des codes d'interaction et de communication dans la classe. Parmi les clefs pour étudier le climat émotionnel dans la classe on étude le rôle que les enseignants jouent á partir de sa propre identité professionnelle, et les messages émotionnels qu'envoient aux éléves parmi les chaînes de communication qui emploient, surtout parmi la communication non verbal. Ce sont les éléments centrales pour construir l'empatie.

Mots clef: climat émotionnel de la classe, rôle des enseignants, identité professionnelle.

He llegado a una estremecedora certeza: soy el elemento decisivo en el aula.

Mi ser, mi persona, es lo que crea el clima de la clase.

Es mi actuar diario en el aula lo que genera sol y calor o tristes nubarrones.

Como profesor poseo el poder tremendo de hacer la vida de un niño miserable o alegre.

Puedo ser un instrumento de angustia o un factor de inspiración.

Puedo humillarlo o hacerlo reír, lastimarlo o fortalecerlo... (Ginnot, 1993).

\section{EL DOCENTE COMO ELEMENTO CENTRAL DEL Clima EMOCIONAL DEL AULA}

Desde el primer día de clase, los docentes son el elemento central que generan el clima del aula (Guil, Loscertales y otros, 1992). Consigo acordarme nítidamente de mí mismo, con nueve años, escondido tras la cabeza del alumno de la fila anterior, seguro de que el profesor no podría fijarse en mí, uno más en un grupo de treinta alumnos, y dedicado con atención a examinar hasta los más ínfimos gestos del nuevo profesor al que el azar me había unido para un largo periodo de 
nueve meses. Mi escasa experiencia como alumno ya me había hecho entender la idea de Ginnot de que un profesor tiene el tremendo poder de hacer la vida de un niño miserable o alegre.

Muchos adultos nos hemos olvidado de los miedos infantiles. Tendemos a quitar importancia a las reclamaciones de los niños frente a sus profesores, porque siempre pensamos que mezclan la realidad con la fantasía. Sin embargo, a veces, la falta de madurez de los niños les lleva a admitir abusos y a tolerar agresiones, simplemente porque vienen de una persona mayor, y porque los niños aprenden, desde muy pequeños, que en sus enfrentamientos con los adultos llevan siempre las de perder. El adulto domina el lenguaje y las técnicas de la comunicación social. Adopta el punto de vista del interlocutor, y tiene encima muchos años de entrenamiento en la mentira. Si hace falta, el adulto encuentra mil caminos para desacreditar las afirmaciones de un niño. Lo he visto demasiadas veces en mis años de colaboración con el Juzgado de Menores: el crío permanece en silencio, con la cabeza gacha, mientras sus padres cuentan, en un espectacular alarde de cinismo, que los hematomas se los hizo en una caída fortuita por una escalera. Y, al final, a solas, el pobre chaval te acaba pidiendo que no le separes de sus padres, porque, a veces, entre paliza y paliza le dan un poco de afecto. Recuerdo de forma particularmente dolorosa la escena de un niño de diez años, severamente maltratado por su padre, defendiéndolo ante la juez de menores con el argumento de que le pegaba porque le quería, cuando, en realidad, lo que le aterraba era repetir en su propia experiencia el abandono y la soledad que había experimentado un amigo suyo cuyos padres habían sido encarcelados. En estas escenas comprendí la enorme importancia, la auténtica prioridad del afecto en la mentalidad infantil, anteponiéndolo incluso a su propia seguridad y a su propio bienestar material.

Cuando analizo la propia experiencia escolar desde mi actual mentalidad de adulto soy capaz de revisar, con una visión crítica, el papel que distintos profesores jugaban en el aula, creando climas educativos muy diferentes: unos positivos y otros cercanos al maltrato infantil. Desde mi actual mentalidad de adulto puedo criticar los abusos que acepté con ocho años. Ahora tengo argumentos. Sé distinguir la injusticia y el castigo desproporcionado; pero, en aquella época no tenía escapatoria, ni siquiera la capacidad de criticar aquellas situaciones. No era sino un niño más, en manos de un adulto que imponía un clima de clase desde su propia concepción de la docencia. A veces, recordando aquella época, me recreo en una ensoñación fantástica: me gustaría volver a vivir los siete y los ocho años con mi capacidad actual de razonamiento y de experiencia. Durante un rato me entretengo en vengar injusticias, detener abusos, desarmar argumentos estúpidos y deshacer mentiras. Pero, en cuanto me he divertido un rato en mis propias fantasías, llego siempre a la misma conclusión: si algún día una divinidad oculta me concediera hacer realidad mi sueño, el sistema escolar me machacaría. $O$, al menos, el sistema escolar que me tocó vivir, y del que puedo hacer un juicio basado en mis doce años de experiencia como alumno de primaria y secundaria. Aún hay instituciones escolares a las que, en realidad, no les importa la inteligencia ni la cultura; en realidad, funcionan 
como un sistema de sumisión, en el cual, para que el niño avance y sobreviva, necesita aceptar las versiones de la inteligencia y de la cultura que en cada caso defiende el intérprete de turno. La misma materia en manos de dos profesores pueden ser mundos muy distantes. Para sobrevivir en estas instituciones hace falta la inexperiencia, el reconocimento infantil de la inferioridad y esa fe ciega e injustificada que los niños tienen en la sabiduría de los adultos. Para ilustrar la idea de Ginnot de que un profesor tiene el tremendo poder de hacer la vida de un niño miserable o alegre, querría partir de la contraposición de tres impresiones de un alumno ante la presencia del profesor en el primer día de clase.

\subsection{El primer día de clase con D. Joaquín, a los ocbo años}

Desde mi mentalidad actual, estoy seguro de que aquel año fue una pesadilla y de que D. Joaquín era un sádico. Un pobre hombre que intentaba compensar sus sentimientos de debilidad y frustración, gozando del dominio que su posición le confería sobre cuarenta críos de ocho años que no podían defenderse. Fuera de clase no era nadie. Inculto y zafio en sus maneras, y servil con los frailes que le daban el sustento, se gozaba al observar nuestra cara de miedo cuando cerraba la puerta de la clase, y se convertía en el dueño y señor de nuestras vidas durante siete horas al día. Disfrutaba con el terror gratuito, gracias al cual conseguía mantener a cuarenta niños pendientes de sus más leves gestos.

El primer día de clase no dejó pasar ni cinco minutos sin confirmar con sus hechos la leyenda negra que nos habían transmitido sus antiguos alumnos. Los animales agresivos necesitan marcar el territorio de caza, y él quiso dejar bien claro, desde el principio, quién era el dueño de la clase.

Muchos profesores nos pedían que sacáramos los libros y nos pusiéramos a estudiar, para poder dedicarse a sus cosas. Asî, podían corregir exámenes, preparar explicaciones, o simplemente gozar de unos minutos de relajo dedicados a la lectura. Fray Eufemio utilizaba los estudios para leer el Breviario, mientras nosotros, mirando al libro, nos evadíamos hacia el lejano oeste galopando junto al caballo de Gary Cooper, o izando las velas de los barcos piratas en los que Errol Flynn enamoraba a Olivia de Haviland.

Sin embargo, desde que D. Joaquín, nada más entrar en clase, pidió que sacáramos los libros y decretó el estudio, me di cuenta de que algo andaba mal. En lugar de relajarse, dedicándose a sus cosas con la habitual indiferencia hacia los alumnos, él se mantuvo alerta, con el cuerpo erguido, girando la vista rápidamente, como un halcón, sobre cualquier ruido o movimiento que pudiera llamar su atención. Por fin, avistó la presa: al pobre Palomo se le había caído un lápiz al suelo, e inocentemente se agachó a recogerlo.

El ruido alertó a la rapaz, y el movimiento del niño lo levantó del asiento en décimas de segundo.

— ¿Usted, venga aquí! - -el crío se acercó, con el lápiz aún en la mano, y una sonrisa de inocencia-. ¿Cómo se llama? apellido-

- Palomo - el proceso de domesticación nos había enseñado a usar sólo el 
—¿Qué estaba haciendo? - preguntó D. Joaquín-.

-Yo, nada.

-iPues, por no hacer nada! - - le cruzó la cara con dos bofetones, el primero del derecho y el segundo con el dorso de la mano; ambos con un ingrediente nuevo: aquel hombre pegaba con fuerza, con rabia, buscando más el dolor físico, que el ingrediente moral del castigo-.

... Estaba verdaderamente enfadado, y a mí me asustaron más sus repentinos cambios de humor, de la sonrisa a la agresión, que los sonoros bofetones. En menos de un cuarto de hora, el primer día, en la primera clase, tuve una clara intuición de lo que iban a ser los próximos nueve meses: cuarenta críos de ocho años, aterrorizados, a merced de la arbitrariedad. El terreno estaba marcado. Él era el dueño. La clase su propiedad. Nos mandaría levantarnos o sentarnos. Nos pegaría si quería, o permitiría nuestra existencia. Y todo ello de forma imprevisible. Él era la ley, el juez y el verdugo.

El mensaje estaba calando, muy hondo, en la conciencia colectiva. Levantó la vista del muñeco aterrorizado que había conseguido, y paseó la mirada por la clase. En un silencio absoluto observó nuestros rostros, fijos en él. Comprendió que las nuevas reglas se estaban interiorizando, y sonrió complacido.

... Miedo. La impresión del miedo me domina. No puedo moverme. Soy claramente consciente de que hará conmigo lo que le dé la gana. No hay reglas. No hay lógica. No hay escapatoria. Me pegará hasta que quiera, y no puedo hacer nada. Tengo la boca seca. Pienso en que estoy sudando. La rabia de la indefensión se me queda en la garganta. Quisiera gritar, decirle que en casa no fallo las cuentas. Quisiera decirle que no es justo; pero no me sale la voz. Ni siquiera puedo mirarle. Me quedo allí, retorciendo una punta del jersey con las manos, intentando dominar los nervios.

-... En aritmética tienes un cero. Y voy a cambiarte los cuatro borradorazos por ocho reglazos. ¿Te parece justo?

Digo que sí con la cabeza, mientras noto en la garganta cómo se me agolpa la rabia. Me parece una ironía que hable de justicia; pero mi colegio ya me ha enseñado a sobrevivir. Sé que un enfrentamiento es peor. Hay que aguantar el trago y dejar que pase. Llevo desde principios de curso adaptándome a la mentalidad de un sádico con poder, y aunque no soy capaz de expresarlo con palabras, sé lo que hay que hacer. A los locos hay que seguirles la corriente. Soy su juguete. Va a divertirse un rato pensando que es alguien, porque consigue aterrorizar a un puñado de críos de ocho años (Esteve, 1998, 47-53).

\subsection{El primer día de clase con D. Federico, a los diez años}

D. Federico fue el amo y señor de nuestras vidas en el curso escolar de 19601961. Arropados por sus duras enseñanzas, la mayor parte de nosotros cumplió los diez años que el legislador había establecido como edad idónea para el ingreso en bachillerato.

Físicamente, D. Federico era un hombre grueso, más bien bajito, de cara redonda y sonrosada, con el pelo engominado y aire pulcro. Aunque la edad de todos nuestros profesores era una cuestión que no solía plantearse, calculo que no 
llegaría a los treinta. Pero, sobre todo, su rasgo físico más característico eran las manos: dos auténticas morcillitas sonrosadas, con los dedos carnosos y redondos. Parecía imposible que aquellas manos pudieran hacer el más mínimo ejercicio de precisión. En reposo, los dedos quedaban separados en las puntas, sin posibilidad de juntarse, por los tocinillos que se acumulaban en las falanges superiores, donde el anillo matrimonial quedaba enterrado en aquel exceso adiposo.

Aún recuerdo con precisión mi primer día de clase con D. Federico. Oculto tras la cabeza del alumno de delante espiaba sus más mínimos movimientos.

En aquel momento, yo era consciente de que había cambiado de amo. Me gustara o no, el destino de mis próximos nueve meses de vida iba a estar unido a las actitudes de aquel hombre, que estaba dedicando su primer día de clase a darnos todo tipo de normas.

Desde el primer momento, yo era consciente de que debía aprenderlas. Conocer sus deseos evitaría las iras del amo. Conocer las normas me permitiría adaptarme. Y a aquellas alturas, aunque aún no hubiera oído hablar de Darwin, tenía perfectamente claro que la adaptación era el único signo real de inteligencia y el único camino para sobrevivir.

Nosotros éramos cuarenta. Él sólo uno. Si yo pegaba el cuerpo al pupitre, él no podía verme. Por contra, el primer día de clase, yo podía dedicarme a analizarlo a él hasta los mínimos detalles. Desde mi puesto de observación, yo intentaba valorar todos los indicios con los que predecir el futuro inmediato.

Para empezar, estaba su mensaje verbal: él quería que su clase, Ingreso C, destacara en todo sobre los otros dos grupos, el A y el B; él quería el más absoluto silencio en clase; orden y pulcritud en nuestras personas, pupitres y pertenencias; él quería acabar el programa de todas las materias en marzo para dedicar el tercer trimestre a repasar; él no quería chicles, ni pipas, ni caramelos en clase; ni tampoco que le interrumpiéramos en sus explicaciones: las preguntas y las dudas debían reservarse para el final de la clase; y, sobre todo ello, él quería trabajo, esfuerzo y disciplina: "El que trabaje y mantenga las normas de conducta, no va a tener problemas conmigo" - prometió-.

A continuación, había un sutil lenguaje de gestos: la expresión corporal puede desmentir o confirmar los mensajes verbales. Y, en ese aspecto, D. Federico emitía señales altamente positivas. Hablaba con el cuerpo relajado y la espalda apoyada en el respaldo de la silla. No existía el más leve indicio de tensión: la mirada se movía lentamente sobre el grupo de clase, sin los giros bruscos del ave de presa dispuesta a caer sobre nosotros. Los niños son capaces de captar todos estos indicadores, aunque los adultos no nos lo creamos, y ellos mismos no sean capaces de explicarlos. Con diez años, yo era capaz de captar la sutil diferencia entre el profesor capaz de escuchar en silencio la pregunta de un niño, intentando comprenderla; y la respuesta precipitada y cortante del profesor molesto por que alguno de los seres inferiores hubiera osado interpelar al amo. El matiz de una sonrisa animándote a seguir, ante una duda al recitar la lección, es captado y traducido por los niños, inmediatamente, desde el lenguaje de los gestos al mundo de los afectos.

Para acabar, los profesores también nos hablaban de su personalidad y de sus actitudes, con el lugar que ocupaban en el espacio. D. Joaquín estaba poco tiempo en la silla, paseaba nervioso por la pizarra y los pasillos de la clase en busca de víctimas, y se sentaba atrás, en el último pupitre, para dominar la clase desde la 
espalda. Fray Eufemio prefería estar en pie, junto a la pizarra; pero raramente se internaba por los pasillos, si no era para ayudar a un alumno en sus tareas, o corregir la posición de un cuerpo doblado contra las normas de la higiene. D. Federico había aposentado su redonda humanidad sobre un sillón con brazos, provisto de un cojincillo plano, y no parecía dispuesto a bajar del trono para repartir latigazos entre los forzados de los bancos.

El curso anterior había leído en casa El Lazarillo de Tormes, y en aquel momento, recordando la lectura, me identifiqué con el protagonista: un pobre crío que debe sobrevivir y adaptarse al dominio de sucesivos amos, y cuya vida va cambiando según el talante y las manías de cada uno de ellos: un ciego, un clérigo, un escudero, un fraile, un capellán, un buldero... De la misma forma, en cada inicio de curso, nosotros cambiábamos de amo, pasando, como Lázaro, del relámpago al trueno, recibiendo coscorrones siempre, a cambio de una escasa comida - gallofa, habría dicho él一, en este caso intelectual.

Cuando D. Federico acabó de hablar pensé que habría de ser buen amo. Y, en efecto, lo fue. Nos pegaba de vez en cuando, porque en aquella época, como tengo dicho, era una costumbre nacional. Pero pegaba con desgana, con la costumbre del funcionario eficiente y aséptico; sin el regocijo morboso de D. Joaquín, ni el ánimo sistemático de arrancar, desde temprana edad, los tiernos brotes del vicio surgidos de la semilla del pecado original, como era el caso de fray Eufemio (Esteve, 1998, 87).

\subsection{El primer día de clase con fray Antonio, a los quince años}

Despues de nueve años de escolaridad, yo pensaba que ya nada podía sorprenderme. El primer día de clase había perdido, hacía años, los componentes de ansiedad, de miedo a lo desconocido, y sobre todo, el sentimiento de quedar en manos de un nuevo amo, omnipotente y arbitrario, cuyas sentencias se convertían en ley con la rapidez del efímero vuelo de las palabras.

En el largo recorrido de mi escolaridad había estado sometido a tan variopinta fauna de profesores, que pensaba que ya nada nuevo me quedaba por descubrir. Los había tenido altos y bajos, fuertes y débiles, eruditos e ignorantes, orgullosos y humildes, temibles y temerosos, caritativos e inhumanos. Los había visto reír con arrogancia; pero también llorar con amargura, hasta descubrir los pies de barro de aquellos a los que en mi infancia había tenido por dioses.

Con mis quince años había conseguido sustituir la ansiedad del primer día de clase, por la curiosidad desapasionada del entomólogo, analizando con interés a un nuevo bicho raro, atento a los menores detalles, pero con la única intención de catalogarlo en la taxonomía adecuada...

Desde el primer momento, fray Antonio se resistió a la clasificación. Licenciado en Lenguas Clásicas por una prestigiosa Universidad española, era uno de los pocos profesores que, en aquella época, daban clase de lo que habían estudiado. Como fraile aportaba una auténtica novedad que rompía con los modelos precedentes, en los que dominaban los gestos severos y el aire ceñudo y triste: fray Antonio era un hombre alegre, al que la risa le brotaba con espontaneidad, limpia y 
clara, sin mezcla de ningún otro componente. La risa bailaba en sus labios porque llevaba la alegría dentro, y no podía salirle otra cosa.

Lo primero que hizo fue intentar responder a nuestra pregunta más acuciante: "Para qué podía servirnos el Griego?".

Y su respuesta tenía mucho sentido:

"El Griego les servirá para descubrir una cultura -nos dijo-. La época clásica, de lo que hoy conocemos como cultura griega, desapareció hace más de veintidós siglos con la conquista romana; sin embargo la cultura griega sobrevivió a la conquista, y dominó de tal manera a los vencedores, que lo mejor de la cultura latina no hizo sino continuar con los modelos griegos.

"Probablemente, a muchos de ustedes les hayan contado la patraña de que el Griego es una lengua muerta que nos habla de una cultura muerta; así que dedicaré gran atención, durante el curso, a convencerles de que la lengua y la cultura griega están vivas. Viven en nosotros: en nuestras costumbres, en nuestros pensamientos, en la ciencia, en el arte, en toda nuestra cultura... Si ponen la atención suficiente, descubrirán que es imposible pasar un solo día sin encontrar por todas partes las huellas de la cultura griega: Si hablan de política discutirán sobre la "demo-cracia", o de cómo destronar al "tyranos" —increíble!, ¿aquello era una velada alusión a Franco? - Si van a divertirse podrán elegir entre ir al "theatron" o al "cinemato-grafo". Si vienen al colegio a estudiar, descubrirán que en "mathemáticas" les hablarán de Pitágoras. En "geo-metría" no podrán evitar a Euclides. En "fysike" tendrán que recuperar las preocupaciones de Arquímedes —un viejo desnudo que no podía dejar de pensar ni en la bañera-. Y además, estudiarán "historia" y "geo-grafia" y "filo-sofia". Al estudiar el Griego comprenderán que todo lo que conocemos como ciencia, pensamiento, arte o cultura, tiene sus raíces en Grecia. Sin conocer la cultura griega perderán ustedes el sentido de los orígenes de todas esas manifestaciones del saber que dan valor a la vida humana. Y si pierden el sentido original, perderán la capacidad de discernir si los hombres hemos mejorado con el paso del tiempo; o si, por el contrario, hemos perdido alguno de los elementos esenciales, alguno de los valores claves, que hicieron posible aquella antigua y formidable explosión del conocimiento.

"¿Saben ustedes que, en la actualidad, Aristóteles sigue siendo traducido, publicado, y leído, hasta agotar las nuevas ediciones?

"Además, si lo leen, descubrirán que aún resulta interesante. El viejo Aristóteles, veinticuatro siglos despues de su muerte, aún sigue dando respuesta a muchas de las preguntas del hombre contemporáneo. ¿Y saben cuál es el secreto? - hizo una pausa, hasta dejar que la pregunta calara hondo, arropada por el silencio, mientras nos miraba de uno en uno, directo a los ojos-. El secreto de Aristóteles está en que supo formular las preguntas esenciales. Supo llegar hasta el fondo del alma, y descubrir las claves ocultas que nos permiten entender al hombre: su vida, su pensamiento, sus preocupaciones, sus sentimientos... Por eso ha resistido el paso del tiempo. Lo que él pensó y escribió no se refería a las modas de la época. Sus escritos nos colocan en el centro de las preocupaciones, que inevitablemente el hombre vuelve a plantearse en cada generación. ¿Qué es el bien? ¿Cómo puedo distinguirlo del mal? ¿Cómo evitar el error para encontrar la verdad? ¿Cómo establecer un gobierno justo?... - - de nuevo el silencio subrayó sus preguntas; mientras, relajado y tranquilo, buscaba nuevos argumentos con los que encender 
nuestro interés por la lengua y la cultura griegas. Todos nosotros permanecíamos en silencio, concentrados en su discurso, devolviéndole la mirada franca y alentadora de quienes descubren el saber en un pensamiento ajeno--.

"¿Sabían ustedes que aún se representa el teatro griego?... Las tragedias de Sófocles y de Eurípides, las comedias de Aristófanes y Menandro... También ellas han resistido el paso del tiempo. Y la razón es la misma que ha mantenido viva la obra de Aristóteles: tratan temas eternos, que, con independencia de la época, vuelven una y otra vez a interrogar la vida de los hombres.

"Probablemente, hayan oído hablar de Electra y de Antígona. Son los personajes centrales de dos tragedias de Esquilo; pero en realidad no son dos personajes: son dos ideas.

"Electra representa la venganza. Es la mujer que, en largos años de sufrimiento, mantiene viva la llama de la venganza hasta que ésta explota como un auténtico volcán, con toda la lava acumulada en su interior.

"Antígona es otra mujer fuerte. Representa la fuerza del amor y el sentido del deber frente a la ley injusta. Antígona encarna el enfrentamiento entre lo que una persona considera justo, y lo que está establecido por la ley.

¿De la misma manera, la Medea de Eurípides representa el despecho de la mujer abandonada por su amante, y Las Troyanas es el primer alegato conocido contra las miserias de la guerra.

"Cada vez que una mujer encuentra a su marido en brazos de otra, pensará como Medea, sentirá como Medea, y en mayor o menor medida reproducirá aquella tragedia que conmovió a los griegos hace dos mil cuatrocientos años. Y en todo este tiempo, la tragedia sigue siendo la misma. Se ha representado miles de veces en los escenarios, porque aún se ha representado muchas más veces en la vida real; porque, aún hoy, los espectadores del teatro reconocen en ella escenas, pensamientos y sentimientos que han visto antes en su propia vida o en las de sus amigos o vecinos.

"Las cifras producen vértigo. ¿Cómo es posible que una obra de teatro siga teniendo interés después de dos mil cuatrocientos años?... —-volvió a dejar un espacio de silencio. Nos había enganchado en el anzuelo de su palabra, con tal fuerza, que el sedal podía recorrer metros y metros, cada vez más lejos, sin que ninguno de nosotros perdiera el hilo de sus argumentos-.

"Parece increíble que ésto pueda suceder; pero el teatro griego sigue teniendo vigencia, porque Sófocles y Eurípides, como Aristóteles, también supieron llegar al fondo del alma humana, a esos últimos reductos en los que se juega el sentido y el valor de nuestra existencia.

"De la misma manera, cada vez que alguien inventa un chiste sobre los "politikos", reproducirá, probablemente, el argumento básico de las comedias de Aristófanes: la diferencia entre lo que piensa de su país el gobernante, engreído por el poder, y lo que piensa la gente del pueblo que sufre las consecuencias de su política. Los aires de grandeza son ridículos, y la comedia griega supo descubrir la diferencia entre la forma en que nos vemos a nosotros mismos, y cómo nos ven los demás. De nuevo, nos encontramos con un tema que seguirá siendo igual hoy y dentro de cien años.

"Probablemente - prosiguió-, han oído ustedes la expresión "tener la cabeza a pájaros" o "tener la cabeza llena de pájaros". La gente usa esta expresión para 
hablar de la persona que confunde la fantasía con la realidad. Ésta es otra de las fuentes inagotables del ridículo, que aún alimentará miles de chistes. Resulta divertido ver a alguien creerse sus propias fábulas, hasta acabar estrellándose con la realidad. Sin embargo, la mayor parte de la gente que utiliza esas expresiones, no sabe que tienen su origen en una comedia griega que lleva el mismo título: Los pájaros.

"La cultura griega... Me gustaría que a lo largo del curso pudieran ser capaces de apreciarla. Si lo intentan, descubrirán su riqueza, su enorme potencial de pensamiento y, más aún, su sorprendente vigencia.

"Piensen, por ejemplo, en la arquitectura y en la escultura griegas. El Renacimiento y el Neoclasicismo, muchos siglos más tarde, volvieron a los modelos griegos: a la pureza de líneas, a la sobriedad y el equilibrio de los diseños de Calícrates, de Mirón y de Fidias. Cada año, miles de turistas sueñan con redescubrir los templos griegos, y acarician la idea de perderse por la islas del mar Egeo, buscando las bellas líneas de viejas construcciones que aún se mantienen en pie...”.

Fray Antonio siguió hablando durante toda la hora, sin que ninguno de los siete magníficos se atreviera a respirar más fuerte de lo debido. Mi taxonomía de los profesores abrió aquel día un nuevo apartado. Hasta entonces no había topado con un verdadero maestro; pero, mientras él hablaba, descubrí una nueva dimensión de lo que se podía hacer en una clase. Nada nos obligaba a escucharle; pero su discurso nos llevaba a seguirle sólo por el calor de sus palabras. Cada idea era una sorpresa, un interrogante que te hacía descubrir una nueva dimensión del mundo, hasta entonces insospechada. Su exposición despertaba ecos que te hacían pensar muchas horas después, fuera de clase, ante pequeños detalles de la vida cotidiana, que ahora, iluminados por una nueva perspectiva, se veían diferentes a como hasta entonces los habíamos entendido. Su pensamiento era capaz de enhebrar lo fundamental, llamando nuestra atención sobre relaciones ocultas a las que el hilo de su pensamiento dotaba de una nueva dimensión. Fray Antonio no hablaba de lo ya pensado, sino que hablaba pensando. Nunca vi a nadie tan enamorado de su asignatura: la lengua y la cultura griegas eran para él un instrumento con el que conocer e interpretar el mundo, y su entusiasmo por comunicarnos lo que para él era importante llegaba a contagiarnos.

En sus clases, nuestro silencio no era una señal de resignación ante el imperio de un nuevo amo poderoso; sino, por primera vez, un signo de respeto intelectual. Lejos de humillarnos, destacando nuestra ignorancia, seguir su pensamiento en silencio nos liberaba de la mediocridad, descubriendo en cada idea nuevos horizontes llenos de sentido y de matices, cargados de relaciones, en las que la cultura griega avanzaba y se extendía a lo largo de la Historia, preñando de significados hasta entonces ocultos hechos muy distantes en el espacio y en el tiempo.

Fray Antonio demoró dos o tres días su introducción sobre la lengua y la cultura griegas, guardando para cada día la sorpresa de un nuevo descubrimiento. Sólo cuando estuvo seguro de que queríamos aprenderlo, nos enseñó el alfabeto griego. 


\section{Las ClaVes del Clima emocional Del aUla}

En esta descripción de las tres diferentes actitudes de un profesor en el primer día de clase, encontramos las claves pedagógicas a partir de las cuales los docentes crean uno u otro clima emocional en el aula: en primer lugar, la expresión más o menos explícita de su propia identidad profesional; y, en segundo lugar, los mensajes emocionales que envían a sus alumnos a través del estilo y los canales de comunicación que utilizan en el aula, básicamente a través de los códigos no verbales. Estos códigos no verbales traslucen el componente comportamental de las emociones, permitiéndonos saber cuáles son los sentimientos de nuestros alumnos. Clásicamente se distinguen tres componentes en la emoción: un componente neurofisiológico, otro conductual y un tercero cognitivo. Las respuestas neurofisiológicas (alteraciones en la respiración, secreciones hormonales, rubor, etc.) son difíciles de controlar por el sujeto, y generalmente se manifiestan en elementos conductuales (expresiones faciales, lenguaje no verbal, tono de voz, etc.); y aunque este componente conductual puede disimularse, generalmente nos permite conocer cuáles son las emociones de un sujeto. Por último, tenemos los sentimientos, es decir, el componente cognitivo, la vivencia consciente de las emociones que entraña siempre un elemento subjetivo: la interpretación personal del sujeto sobre la situación que le hace emocionarse (Bisquerra, 2003).

\subsection{La identidad profesional del docente}

Para hablar de la construcción de la identidad profesional tengo varios caminos, puedo citar los trabajos de Huberman (1989) sobre los ciclos de vida de los docentes, o basarme en las grabaciones de vídeo realizadas durante años sobre más de dos mil futuros profesores, a partir de las cuales inferí que las ideas previas, algunas irracionales, con las que los profesores se inician en la enseñanza, dominan las actitudes con las que se enfrentan a sus alumnos, y consecuentemente el clima de clase que generan; finalmente, me decido a hablar desde mi experiencia; a contar mi historia de vida como un docente que ya lleva en la profesión más de treinta años; a contar mis propios inicios en la docencia, a hablar de mis miedos y del proceso de búsqueda de mi propia identidad profesional; de mi propio proceso de mejora y de maduración profesional, a hablar de cómo entiendo hoy mi profesión, cómo preparo mis clases, qué me importa, qué valor doy a mi trabajo y cómo he evolucionado a lo largo del tiempo. La razón fundamental de esta elección se basa en mi convicción de que el principal problema de cualquier persona que comienza en una profesión - en la docencia o en cualquier otra - es la dificultad de definir el propio papel profesional; o mejor, definir la propia identidad profesional; es decir, el papel que creemos que debemos asumir en nuestro trabajo profesional. Después de muchos años empeñado en la formación inicial de profesores de secundaria he llegado a la terrible certeza de que la mayor parte de nuestros profesores debutantes no ha dedicado ni una hora de su tiempo a intentar 
delimitar el papel profesional que van a jugar cada día al entrar en una clase. La mayoría repite esquemas de actuación de otros profesores, sin preguntarse siquiera si éstos son adecuados para los alumnos y las situaciones de enseñanza en las que ellos van a iniciarse en la profesión docente. La cuestión no es banal: las actitudes básicas de los profesores, las ideas con las que se enfrentan a los alumnos rigen la creación del clima emocional del aula. Si alguien se siente orgulloso de ser profesor porque desde el sadismo y la miseria personal de D. Joaquín puede compensar su falta de valor en el mundo de los adultos aterrorizando a un grupo de niños de ocho años, sus actitudes hacia los alumnos son fácilmente predecibles. Si, como fray Eufemio, pienso que yo estoy en la enseñanza para enderezar los brotes torcidos que inevitablemente surgirán como consecuencia inevitable del pecado original, mi actitud hacia los alumnos también será diferente, y de ella se generará un clima de clase distinto.

No creo que sea bueno definir una única identidad profesional como un modelo al que todos los profesores deban amoldarse. La identidad profesional debe redefinirse en cada situación de enseñanza y en cada contexto concreto en el que hayamos de trabajar, ya que sería iluso pretender los mismos objetivos y jugar el mismo papel profesional en el trabajo con niños de educación infantil o en la formación de titulados en Medicina. Ésta es una razón más para centrarme en una descripción de mi propia experiencia: yo sé cómo definí mi propia identidad profesional y sé describirla; pero no la puedo elevar a modelo universal.

Sin embargo, en mis treinta años en la profesión he visto a demasiados docentes jugar papeles inadecuados, enfocar su trabajo de profesores desde planteamientos tan sin sentido que, desde que los he visto, he pensado que iban a fracasar $\mathrm{y}$, lamentablemente, pocas veces me he equivocado; y lo peor de estos errores es que no sólo hacen daño a los alumnos, sino que, a la larga, el profesor que los vive se hace daño a sí mismo (Esteve, 1994).

Los papeles inadecuados que pueden jugar los profesores son infinitos. Tantos, que necesitaría otro artículo para desarrollarlos; pero a modo de muestra hablaré de los más frecuentes. El primero, sin duda, es el de los que piensan que para ser un buen profesor lo único realmente necesario es conocer profundamente el contenido de la materia que van a impartir. Es el caso ese, tan repetido, en el que oímos a los alumnos hablar de que alguien sabe su materia pero es un pésimo profesor. Desde esta perspectiva suele confundirse el papel de comunicador que el profesor debe desempeñar con el papel de conferenciante aséptico, más interesado en demostarse a sí mismo lo bien que se domina la materia, que en hacerla asequible a los alumnos. Como desarrollo más adelante, yo aprendí las destrezas sociales que hacen falta para ser profesor por el método bárbaro del ensayo y error. Ahora, en los inicios del siglo XXI, hay disponible suficiente bibliografía para no tener que exponerse a una acumulación de errores que nos haga comenzar nuestra carrera universitaria desde un sentimiento de fracaso y de inadecuación que puede marcarnos para siempre. 
Un segundo papel inadecuado que encontramos frecuentemente, sobre todo en la Universidad, es el del selector social. Profesores que se creen delegados por alguna divinidad vengativa para examinar a los alumnos decidiendo quienes son $\mathrm{O}$ no dignos de obtener el título universitario que tanto esfuerzo les costó a ellos obtener. El modelo abunda en las ingenierías y es casi una gracia en las secciones de ciencias exactas. En este grupo se encuadra el desgraciado que recibe a los alumnos de primer curso de una carrera de Ingeniería con el saludo de: "Espero que tengan ustedes mucho interés por estudiar esta carrera que ya me encargaré yo de quitárselo". Desde este modelo se dedican a poner trampas semánticas en los enunciados de los problemas; a buscar la variante más retorcida de una aplicación, imposible de encontrar en la vida real, para hundir al mayor número de alumnos en los exámenes; y a explicar en clase desde el supuesto de que quienes no son capaces de estar a su altura son indignos de seguir esa carrera y, por tanto, no merecen mucha explicación complementaria. El resultado es que para aprobar su materia los alumnos tienen que ir a una academia privada. Esto seguirá así hasta que, un día, algún rector con mediano sentido común decida echarlos a la calle y contratar en su lugar a los profesores de la academia. Lo más triste que he oído en estos treinta años de Universidad es la frase de un estudiante de Ingeniería que hablando de un compañero suyo, premio nacional de bachillerato, decía: "Jamás aprobará el primer curso; su padre es carnicero y no tiene dinero para mandarlo a las academias". Resulta socialmente inaceptable que le entreguemos a un profesor a cien alumnos, de los que el más tonto tiene un 7,36 en selectividad, y que el profesor no consiga aprobar más que a diez o doce. ¿Qué pretenden hacernos creer? ¿Que unos chicos y chicas que han mantenido una excelente calificación media durante el bachillerato se han vuelto todos ellos vagos y tontos de repente? ¿Cuánto tiempo nuestra sociedad les concederá el derecho de hundir a los mejores de nuestros jóvenes, sin hacer nada por ayudarles? Desde esta perspectiva, en la que el profesor entra en clase el primer día despreciando a sus alumnos por su escaso nivel intelectual, las relaciones interpersonales en clase se convierten en una simple lucha por la supervivencia: supervivencia del alumno frente a las trampas del profesor para eliminarlo del sistema educativo, y supervivencia del profesor que sólo conseguirá mantenerse en su puesto tratando a sus alumnos como enemigos de los que tiene que defenderse.

Completaré mi galería de retratos con un tercer papel inadecuado: el del académico extraterrestre. Se trata de una especie profesoral menos dañina para el alumno que las anteriormente descritas, pero que a la larga suele hacer daño al mismo profesor que decide jugar este papel. Me refiero a esos profesores que reniegan de serlo, centrando su identidad en la investigación y olvidando que, después de todo, la Universidad nos paga por enseñar a las nuevas generaciones. Olvidan que, como se desarrolla más adelante, somos intermediarios entre el saber acumulado durante siglos en una especialidad científica y los jóvenes que se acercan a aprenderla. Ellos se refugian en su investigación, cada vez más especializada, hasta acabar, en algunos casos, perdiendo el contacto con los alumnos; o peor aún, 
con el resto de los compañeros y con la misma realidad. Siempre he defendido que la enseñanza universitaria debe tener como referente la propia investigación del profesor, que ha de explicar a sus alumnos desde una síntesis de lo mejor que cada uno ha estudiado, de lo mejor que se ha publicado en su materia y desde su propia experiencia de investigación; pero esto no puede hacernos olvidar que acumulamos el saber para comunicarlo. Por tanto, muchas de nuestras horas de estudio cobran su auténtico sentido cuando las ofrecemos a nuestros alumnos para ayudarles en su aprendizaje, orientando su estudio y su forma de ver la materia que enseñamos desde las claves que nosotros hemos tardado años en descubrir.

Por esta razón, pensé que tenía más sentido y más valor hablar desde mi experiencia; en cualquier caso, ahí queda mi reflexión, como una historia más para estudiar la relación entre nuestras identidades profesionales y los climas emocionales que creamos en el aula.

Llevo mucho tiempo diciendo que la enseñanza es una profesión ambivalente. En ella te puedes aburrir soberanamente, y vivir cada clase con una profunda ansiedad; pero también puedes estar a gusto, rozar cada día el cielo con las manos, y vivir con pasión el descubrimiento que, en cada clase, hacen tus alumnos.

Como casi todo el mundo, yo me inicié en la enseñanza con altas dosis de ansiedad; quizás porque, como he escrito en otra parte, nadie nos enseña a ser profesores y tenemos que aprenderlo nosotros mismos por ensayo y error. Aún me acuerdo de mi primer día de clase, un aula enorme, con más de doscientos alumnos, en la Universidad Complutense de Madrid y en los años finales del franquismo: toda mi seguridad superficial se fue abajo al oír una voz femenina a mi espalda: "QQué cara de crío. A éste nos lo comemos!". Aún me acuerdo de mi miedo a que se me acabara la materia que había preparado para cada clase, a que un alumno me hiciera preguntas comprometidas, a perder un folio de mis apuntes y no poder seguir la clase... Aún me acuerdo de la tensión diaria para aparentar un serio academicismo, para aparentar que todo estaba bajo control, para aparentar una sabiduría que estaba lejos de poseer...

Luego, con el paso del tiempo, corrigiendo errores y apuntalando lo positivo, pude abandonar las apariencias y me gané la libertad de ser profesor: la libertad de estar en clase con seguridad en mí mismo, con un buen conocimiento de lo que se puede y lo que no se puede hacer en una clase; la libertad de decir lo que pienso, de ensayar nuevas técnicas para explicar un tema, de cambiar formas y modificar contenidos. Y con la libertad llegó la alegría: la alegría de sentirme útil a los demás, la alegría de una alta valoración de mi trabajo, la alegría por haber escapado a la rutina convirtiendo cada clase en una aventura y en un reto intelectual.

El camino y la meta me los marcó Unamuno, el viejo rector de la Universidad de Salamanca, en una necrológica de Giner de los Ríos, leída por azar en el Boletín de la Institución Libre de Enseñanza:

Era tan hombre y tan maestro, y tan poco profesor -el que profesa algo-, que su pensamiento estaba en continua y constante marcha, mejor aun, conocimiento... y 
es que no escribía lo ya pensado, sino que pensaba escribiendo como pensaba hablando, pensaba viviendo, que era su vida pensar y sentir y hacer pensar y sentir (Unamuno, 1917, 60).

... "Era su vida pensar y sentir y hacer pensar y sentir”... Miguel de Unamuno y su preocupación por enlazar pensamiento y sentimiento. Una pista más de la importancia de los elementos emocionales unidos a la dimensión intelectual en el trabajo del profesor. Nunca encontré una mejor definición del magisterio: dedicar la propia vida a pensar y sentir, y a hacer pensar y sentir; ambas cosas juntas. Muchos colegas, en las distintas etapas de la enseñanza, coinciden en este punto. M. ${ }^{a}$ Carmen Díez, desde la escuela primaria, expresa así su visión actual de la enseñanza: "Ahora entiendo la escuela como un sitio adonde vamos a aprender, donde compartimos el tiempo, el espacio y el afecto con los demás; donde siempre habrá alguien para sorprenderte, para emocionarte, para decirte al oído algún secreto magnífico" (Diez, 1998). Fernando Corbalán, desde la enseñanza secundaria, tras hablarnos de que en clase tenemos que divertirnos, buscar el ansia de saber y propiciar una atmósfera de investigación, concluye:

Y no se piense que sólo se abre la mente a los alumnos. También la del profesor se expande y se llena de nuevos matices y perspectivas más amplias, y funciona la relación enriquecedora en los dos sentidos. Mi experiencia, al menos, me dice que algunos de los juegos y problemas con los que he disfrutado, y que sigo utilizando, han tenido su origen en la dinámica de la clase... Y cuando se crea esa atmósfera mágica en clase, con los fluidos intelectuales en movimiento, pocas actividades hay más placenteras (Corbalán, 1998).

Hace tiempo, descubrí que el objetivo último de un profesor es ser maestro de humanidad. Lo único que de verdad importa es ayudarles a comprenderse a sí mismos y ubicar el sentido de su profesión en el contexto del mundo que les rodea. Para ello, no hay otro camino más que rescatar, en cada una de nuestras lecciones, el valor humano del conocimiento: todas las ciencias tienen en su origen a un hombre o una mujer preocupados por desentrañar la estructura de la realidad. Alguien, alguna vez, elaboró los conocimientos del tema que explicas, como respuesta a una preocupación vital. Alguien, sumido en la duda, inquieto por una nueva pregunta, elaboró los conocimientos del tema que mañana te toca explicar. Y ahora, para hacer que tus alumnos aprendan la respuesta, no tienes otro camino más que rescatar la pregunta original. No tiene sentido dar respuestas a quienes no se han planteado la pregunta; por eso, la tarea básica del docente es recuperar las preguntas, las inquietudes, el proceso de búsqueda de los hombres y mujeres que elaboraron los conocimientos que ahora figuran en nuestros libros. La primera tarea es crear inquietud, descubrir el valor de lo que vamos a aprender, recrear el estado de curiosidad en el que se elaboraron las respuestas. Para ello hay que abandonar las profesiones de fe en las respuestas ordenadas de los libros, hay que volver las miradas de 
nuestros estudiantes hacia el mundo que nos rodea y rescatar las preguntas iniciales obligándoles a pensar.

Cada día, antes de explicar un tema, necesito preguntarme qué sentido tiene el que yo me ponga ante un grupo de alumnos para hablar de esos contenidos, qué les voy a aportar, qué espero conseguir. Y luego, cómo enganchar lo que ellos saben, lo que han vivido, lo que les puede preocupar, con los nuevos contenidos que voy a introducir. Por último me lanzo un reto: me tengo que divertir explicándolo, y esto es imposible si cada año repito la explicación del tema como una salmodia, con la misma gracia en el mismo sitio y los mismos ejemplos; llevo treinta años como profesor universitario oyéndome explicar los temas, en algunas ocasiones, repitiéndolos dos o tres veces en distintos grupos; he calculado que me jubilo el año 2021 y estoy seguro de que moriré de aburrimiento si me oigo año tras año repitiendo lo mismo, con mis papeles cada vez más amarillos y los rebordes carcomidos. La renovación pedagógica, para mí, es una forma de egoísmo: con independencia del deseo de mejorar el aprendizaje de mis alumnos, la necesito como una forma de encontrarme vivo en la enseñanza, como un desafío personal para investigar nuevas formas de comunicación, nuevos caminos para hacer pensar a mis alumnos... "pensaba hablando, pensaba viviendo, que era su vida pensar y sentir y hacer pensar y sentir...". Desde esta perspectiva, la enseñanza recupera cada día el sentido de una aventura que te rescata del tedio y del aburrimiento, y entonces encuentras la libertad de expresar en clase algo que te es muy querido. Inmediatamente recibes la respuesta: cien alumnos pican el anzuelo de tu palabra y ya puedes dejar correr el sedal, modulas el ritmo de tu explicación a la frecuencia que ellos emiten con sus gestos y sus preguntas, y la hora se pasa en un suspiro - también para ellos-. Y entonces descubres la alegría: ese momento de magia, el sentimiento de empatía con los alumnos, la certeza de estar compartiendo la misma aventura intelectual te recompensa las horas de estudio y te hace sentirte útil en la enseñanza.

No hay mejor regalo de los dioses que encontrar un maestro. A veces tenemos la fortuna de encontrar a alguien cuya palabra nos abre horizontes antes insospechados, nos enfrenta con nosotros mismos rompiendo las barreras de nuestras limitaciones; su discurso rescata pensamientos presentidos que no nos atrevíamos a formular, e inquietudes latentes que estallan con una nueva luz. Y, curiosamente, no nos sentimos humillados por seguir el curso de un pensamiento ajeno; por el contrario, su discurso nos libera y nos ensancha creando en nosotros un juicio paralelo con el que reestructuramos nuestra forma de ver la realidad; y luego, extinguida la palabra, aún encontramos los ecos que rebotan en nuestro interior obligándonos a ir más allá, a pensar por nuestra cuenta, a extraer nuevas conclusiones que no estaban en el discurso original... Éste es el objetivo: ser maestros de humanidad... a través de las materias que enseñamos, o quizás, a pesar de las materias que enseñamos; recuperar y transmitir el sentido de la sabiduría; rescatar para nuestros alumnos, de entre la maraña de la ciencia y la cultura, el sentido de lo fundamental permitiéndoles entenderse a sí mismos y explicar el mundo que les 
rodea. Éstas son la ideas con las que actualmente acudo a cada clase, y desde ellas percibo un clima de reflexión en cada clase, en proporción directa a mi capacidad de relacionar lo que tengo que explicar cada día con los interrogantes que previamente me he preocupado de sembrar entre los alumnos.

He hablado de mis precarios inicios en la enseñanza, y de mi visión actual tras treinta años de recorrido profesional; pero, para ayudar a otros a recorrer el mismo camino, tengo ahora que hablar del proceso intermedio, e, inevitablemente, de las dificultades a sortear.

El primer problema, como he dicho, consiste en perfilar la propia identidad profesional. Esto implica cambiar tu mentalidad, desde la posición del alumno que siempre has sido, hasta descubrir en qué consiste ser profesor. Y aquí aparecen los primeros problemas, porque hay personas que no aceptan la realidad del trabajo de ser profesor. Las dificultades suelen ser distintas para unos u otros profesores.

Para algunos, el peor problema es la idealización: se enfrentan a la enseñanza con una imagen idealizada en la que predominan los tópicos sobre lo que el buen profesor "debe hacer", lo que "debe pensar" y lo que "debe evitar"; pero sin aclarar en términos prácticos cómo actuar, cómo enfocar los problemas de forma positiva y cómo eludir las dificultades más comunes. Han aprendido, mejor o peor, los contenidos de enseñanza a transmitir, pero no saben cómo organizar una clase, ni cómo ganarse el derecho a ser oído. Así, han aceptado en su interior, como dogma de fe, la importancia de la motivación para el aprendizaje significativo: «el buen profesor debe motivar a sus alumnos"; pero nadie se ha preocupado de que aprendieran de forma práctica diez técnicas específicas de motivación. Por estos caminos, al llegar al trabajo práctico en la enseñanza, el profesor novato se encuentra con que tiene claro el modelo de profesor ideal, pero no sabe cómo hacerlo realidad. Tiene claro lo que debería hacer en clase, pero no sabe cómo hacerlo. El choque con la realidad dura dos o tres años (Vonk, 1983; Veenman, 1984; Vera, 1988); en ellos el profesor novato tiene que solucionar los problemas prácticos que implica entrar en una clase, cerrar la puerta y quedarse a solas con un grupo de alumnos. En este aprendizaje por ensayo y error, uno de los peores caminos es el de querer responder al retrato robot del profesor ideal; quienes lo intentan descubren la ansiedad de comparar, cada día, las limitaciones de una persona de carne y hueso con el fantasma etéreo de un estereotipo ideal. Desde esta perspectiva, si las cosas salen mal es por que yo no valgo, por que yo no soy capaz de dominar la clase; y, de esta forma, los profesores novatos se ponen a sí mismos en cuestión, $\mathrm{y}$, a veces, cortan los canales de comunicación con los compañeros que podrían ayudarles: ¿cómo reconocer ante otros que yo tengo problemas en la enseñanza, si el "buen profesor" no "debe" tener problemas en clase? Como señala Fernández Cruz (1995), la identidad profesional se alcanza tras consolidar un repertorio pedagógico y tras un periodo de especialización, en el que el profesor novato tiene que volver a estudiar temas y estrategias de clase, ahora desde el punto de vista del profesor práctico y no del estudiante universitario. 
Para otros profesores, el problema de la identidad profesional es mucho más grave. Como señala Fernando Corbalán (1998): “La inmensa mayoría de los profesores nunca tuvimos una vocación clara de enseñantes... Estudiamos una carrera para otra cosa (matemático profesional, químico, físico...)". En efecto, nuestros profesores se forman en unas Facultades que, ni por asomo, pretenden formar profesores. En ellas predomina el modelo del investigador especialista. Como resultado de este modelo, el profesor debutante debe reciclarse desde los conocimientos especializados en los que se ha formado durante los últimos cinco años de su vida, pensando no en la investigación sino en la docencia. Y, en este punto, se supone que el profesor no necesita un aprendizaje específico. Nuestro sistema de formación de profesores presupone que el simple dominio de la materia permite obtener éxito enseñándola. Al parecer, nadie se ha puesto a pensar en el problema de identidad que sobreviene a nuestro profesor novato cuando se enfrenta a una clase repleta de estudiantes que están bastante lejos de sentir entusiasmo por la materia que uno debe explicar. El sentimiento de error y de autocompasión se apodera de algunos de nuestros profesores y, a veces, perdura hasta el final de su vida profesional. Él es un investigador, un especialista, ha pasado dos veranos en un archivo preparando su tesis entre documentos originales que él es capaz de descifrar... ¿por qué le obligan ahora a enseñar Historia General? Y, además, descubre horrorizado que los alumnos no tienen el menor interés por la Historia, y que temas claves de su especialidad —como el apasionante tema de su tesis— se despachan con dos párrafos en la mayor parte de los libros al uso. Para colmo, nuestro futuro profesor se da cuenta de que no sabe cómo organizar una clase, cómo lograr un mínimo orden que permita el trabajo y cómo ganarse la atención de los alumnos. Aquí, el problema de perfilar una identidad profesional estable pasa por un auténtico proceso de reconversión, en el que el elemento central consiste en comprender que la esencia del trabajo del profesor es estar al servicio del aprendizaje de los alumnos. ¡Qué duro resulta comprender esto a la mayor parte de nuestros profesores! Ellos son investigadores, especialistas, químicos inorgánicos o físicos nucleares, medievalistas o arqueólogos, ¿por qué van ellos a rebajar sus niveles de conocimientos a la mentalidad de un grupo de adolescentes bárbaros? ¡Hay que mantener el nivel! — gritan exaltados-, y ello significa, en la práctica, que dan clase para dos o tres privilegiados, mientras el resto de los alumnos van quedando descolgados. Y además, hasta el fin de sus días, vivirán la enseñanza rumiando la afrenta de que la sociedad les obligue a abandonar el Olimpo de su investigación para mantener contacto un grupo de adolescentes. Por contra, algunos profesores consiguen estar a gusto en su trabajo, y descubren que esto pasa, necesariamente, por partir de una actitud de servicio hacia los alumnos, por el reconocimiento de la ignorancia como el estado inicial previsible, por aceptar que la primera tarea es encender el deseo de saber, por aceptar que el trabajo consiste en reconvertir lo que sabes para hacerlo accesible a un grupo de adolescentes... Mi viejo maestro universitario, en mis primeros años de trabajo en la Universidad de Madrid, me decía que enseñar al que no sabe está catalogado, oficialmente, entre las obras de 
misericordia; y, en efecto, hace falta un cierto sentido de la humildad para aceptar que tu trabajo consiste en estar a su servicio, en responder a sus preguntas sin humillarlos, en esperar algunas horas en tu despacho por si alguno quiere una explicación extra, en buscar materiales que les hagan asequible lo esencial, y en recuperar lagunas de años anteriores para permitirles acceder a los nuevos conocimientos. Lo único verdaderamente importante son los alumnos... Esa enorme empresa que es el sistema educativo no tiene como fin nuestro lucimiento personal; nosotros estamos allí para transmitir la ciencia y la cultura a las nuevas generaciones, para transmitir los valores y las certezas que la humanidad ha ido recopilando con el paso del tiempo, y advertir a las nuevas generaciones del alcance de nuestros grandes fracasos colectivos. Ésa es la tarea con la que hemos de llegar a identificarnos.

\subsection{Empatía y comunicación en las relaciones con los alumnos}

El segundo problema a solucionar para ganarse la libertad de estar a gusto en clase hace referencia a nuestro papel de interlocutor. Un profesor es un comunicador, es un intermediario entre la ciencia y los alumnos, que necesita dominar las técnicas básicas de la comunicación. Además, en la mayor parte de los casos, las situaciones de enseñanza se desarrollan en un ámbito grupal, exigiendo de los profesores un dominio de las técnicas de comunicación grupal. Por tanto, ese proceso de aprendizaje inicial, que ahora se hace por ensayo y error, implica entender que una clase funciona como un sistema de comunicación e interacción. Una buena parte de las ansiedades y los problemas de los profesores debutantes, que luego generan un clima de ansiedad y confrontación en el aula, se centran en este ámbito formal de los canales de comunicación en el aula; es decir, de lo que se puede y lo que no se puede decir o hacer en una clase.

El profesor novato descubre enseguida que, además de los contenidos de enseñanza, necesita encontrar unas formas adecuadas de expresión, en las que los silencios son tan importantes como las palabras, en las que el uso de una expresión castiza puede ser simpática o hundirnos en el más espantoso de los ridículos. Como hemos visto antes, desde el primer día de clase nuestros alumnos analizan nuestra personalidad y nuestros mensajes verbales y gestuales. Desde el primer día, anudan la esperanza de una relación positiva, o levantan la guardia para resistir nueve meses con el menor daño posible. Desde el primer día buscan nuestros límites para ajustar sus respuestas al clima de clase que nosotros hemos creado. Por tanto, el problema no consiste sólo en presentar correctamente nuestros contenidos, sino también en saber escuchar, en saber preguntar y en distinguir claramente el momento en que debemos abandonar la escena. Para ello hay que dominar los códigos y los canales de comunicación, verbales, gestuales y audiovisuales; hay que saber distinguir los distintos climas que crean en el grupo de clase los distintos tonos de voz que el profesor puede usar: un tono grave y pausado induce al grupo a la reflexión, mientras que si queremos animar un debate debemos subir 
algo el tono de voz... (Esteve, 1997). Los profesores experimentados saben qué lugar físico deben ocupar en una clase, dependiendo de lo que ocurra en ella; saben interpretar las señales gestuales que emiten los alumnos para regular nuestro ritmo de clase, y el dominio de estas y otras habilidades de comunicación requiere entrenamiento, reflexión y una constante actitud de autocrítica para depurar nuestro propio estilo docente. Al final, conseguimos ser dueños de nuestra forma de estar en clase, conseguimos comunicar lo que exactamente queremos decir, y logramos mantener una corriente de empatía con nuestros alumnos (Bisquerra, 2002).

Otro obstáculo serio a superar, quizás el que genera en los novatos la mayor ansiedad, es el problema de la disciplina. En realidad, es un problema muy unido a nuestros sentimientos de seguridad y a nuestra propia identidad como profesores. En este tema he visto de todo: desde colegas que entran el primer día en clase pisando fuerte, con aires de matón de barrio, porque alguien les ha dado el viejo consejo de que no pueden sonreír hasta Navidad, hasta colegas desprotegidos e indefensos, incapaces de soportar el más mínimo conflicto personal. Entre esos dos extremos que van desde la indefensión hasta las respuestas agresivas, el profesor tiene que encontrar una forma de organizar a la clase para que trabaje con un orden productivo. $\mathrm{Y}$, en cuanto comienza a hacerlo, descubre que esto tampoco se lo han enseñado. Se supone que el "buen profesor" debe saber organizar la clase, pero en pocas ocasiones se le ha contado al futuro profesor dónde está la clave para que el grupo funcione sin conflictos. El viejo supuesto, según el cual, "para enseñar una asignatura lo único realmente importante es dominar su contenido" encuentra en este campo su negación más radical. Entonces, el profesor descubre que debe atender otras tareas distintas a las de enseñar: tiene que definir funciones, delimitar responsabilidades, discutir y negociar los sistemas de trabajo y de evaluación, hasta conseguir que el grupo trabaje como tal. Una vez que se ha instaurado un clima de trabajo y de corresponsabilidad en clase, la convivencia de todos se hace mucho más agradable. Y esto requiere una atención especial a la que también hay que dedicar un cierto tiempo. El razonamiento y el diálogo son las mejores armas, junto con el convencimiento de que los alumnos no son enemigos de quienes tienes que defenderte. Mi experiencia me dice que los alumnos son seres esencialmente razonables; es posible que, si te dejas, intenten ablandarte y bajar algo tus niveles de exigencia, pero si la razón te asiste y en ella fundas tu propia seguridad, los alumnos saben descubrir muy bien cuáles son los límites. Éste es el problema de la empatía que de nuevo se constituye en un elemento central para hablar del clima emocional del aula (Hoffman, 2002).

La Academia de la Lengua define la empatía como: "Identificación mental y afectiva de un sujeto con el estado de ánimo de otro". De hecho, etimológicamente, viene del griego "en-pathos" (padecer en el lugar del otro). El primer escalón de la empatía es el reconocimiento del otro, la aceptación del otro como persona; por eso, cualquier actuación educativa que ataque la libertad o la dignidad de nuestros alumnos supone una ruptura del clima de empatía en clase. Un profesor no puede 
afirmar verbalmente que respeta las opiniones de sus alumnos, si, mientras alguno de ellos le pregunta, mira hacia otra parte con cara de fastidio. Nuestros alumnos, como dije desde el principio, captan nuestros códigos gestuales como manisfestación externa de nuestros sentimientos. La aceptación del otro viene luego seguida del interés real por los sentimientos del otro. ¿Cómo se sienten los alumnos en mi aula? ¿Cuáles son las reacciones que generan en ellos mis intervenciones y mis actitudes? Sin una preocupación constante por responder a estas dos preguntas resulta difícil generar un sentimiento de empatía, una conexión emocional con el grupo de clase. Ya desarrollé en otra publicación anterior el concepto de "línea de retorno" (Esteve, 1997), referido a la emisión de señales por parte de los alumnos de múltiples mensajes que nos permiten ir conociendo en cada momento los sucesivos cambios de estado en las emociones de nuestros alumnos. Interés, cansancio, aburrimiento, ansiedad, miedo a ser llamado a la pizarra... cada uno de estos estados de ánimo se ven reflejados continuamente en los códigos gestuales de nuestros alumnos. Pongo un ejemplo muy simple: el profesor pide un voluntario para pasar a la pizarra y nadie sale; pero, inmediatamente la clase se divide en dos bandos: los que están dispuestos a salir si el profesor los llama miran hacia él con la cara alta; los que temen ser llamados bajan la cabeza hacia sus cuadernos procurando pasar inadvertidos. Los códigos gestuales de nuestros alumnos reflejan sus estados de ánimo, por eso los considero la "línea de retorno" que nos permite saber la calidad de la recepción de nuestros mensajes en el aula. Saber escrutar y descodificar correctamente estos mensajes es la base más sólida sobre la que constituir un permanente sentimiento de empatía con nuestros alumnos (Güell y Muñoz, 2003). El profesor, como recomendaba Napoleón a sus generales, tiene que saber en todo momento cuál es el estado de ánimo del grupo que dirige; y para ello no hay mejor método que compartir con ellos sus sentimientos, seguir el curso de sus emociones; "padecer con" es el sentido etimológico de la palabra simpatía.

Por último, nos queda el problema de adaptar los contenidos de enseñanza al nivel de conocimientos de los alumnos. El profesor novato tiene que entender que está al servicio de los alumnos, tiene que desprenderse de los estilos académicos del investigador especialista, y adecuar su enfoque de los conocimientos para hacerlos asequibles a su grupo de clase (Álvarez, 2001). De nuevo aparece aquí el problema de la empatía. Yo también protesto por el bajo nivel con el que llegan mis alumnos a la Universidad, pero protestar no sirve de nada, tienes los alumnos que tienes, y con ellos no hay más que una alternativa: o los enganchas en el deseo de saber, o los vas dejando tirados conforme avanzas en tus explicaciones. Hay quien, en salvaguarda del nivel de enseñanza, adopta la segunda opción; pero a mí siempre me ha parecido el reconocimiento implícito de un fracaso; quizás porque, como dije antes, hace tiempo que descubrí que en cualquier asignatura, lo único importante es ser maestro de humanidad.

$\mathrm{Y}$ ahora, ya, el tiempo corre en mi contra. He hecho lo que quería hacer, y estoy donde quería estar. Es posible que mucha gente piense que ser profesor no es algo socialmente relevante, pues nuestra sociedad sólo valora el poder y el 
dinero; pero a mí me queda el desafío del saber y la pasión por comunicarlo. Me siento heredero de treinta siglos de cultura, y responsable de que mis alumnos asimilen nuestros mejores logros y extraigan consecuencias de nuestros peores fracasos. Y, junto a mí, veo a un nutrido grupo de colegas, que desde las escuelas de primaria de las zonas rurales más apartadas, y desde los secundarios de los barrios más conflictivos, están orgullosos de ser profesores, trabajando día a día por mantener en nuestra sociedad los valores de la cultura y el progreso... entre ellos hay valiosos maestros de humanidad: hombres y mujeres empeñados en enseñar a sus alumnos a enfrentarse consigo mismos desde el preescolar hasta la Universidad.

\section{A MODO DE CONCLUSIÓN}

El clima emocional del aula lo construye el profesor a partir de dos elementos básicos: 1. La identidad profesional con la que afronta la relación educativa; es decir, la definición personal que hace de su propio papel como profesor, y desde el cual enfoca las relaciones con sus alumnos con muy distintas actitudes y estrategias. 2. Las destrezas de interacción y comunicación con las que el profesor afronta la relación educativa.

Después de trabajar durante veinte años con circuitos cerrados de televisión en los programas de Inoculación de estrés y de Aprendizaje de destrezas sociales ante situaciones potencialmente conflictivas (Esteve, 1997) puedo afirmar, sin dudas, que en este tema es el profesor quien tiene la iniciativa: las posibles actitudes negativas de los alumnos son reactivas; es decir, se elaboran con los sentimientos y actitudes que los profesores producen desde el primer día de clase, generando respeto o rechazo, a partir de la lectura emocional que los alumnos hacen de tales actitudes y sentimientos.

Sin embargo, desde el mismo momento en que se producen, las reacciones emocionales de los alumnos se convierten en un elemento más de la relación educativa; ya que los profesores las captan inmediatamente, a partir de los códigos gestuales de los alumnos, e inician con ellas una cadena imparable de acción-reacción que, en muchos casos, está en la génesis de las reacciones agresivas de los alumnos y de las actuaciones de los profesores, incapaces de mantenerse en esa banda intermedia de actuación que marcan los dos límites que un profesor jamás tendría que sobrepasar: las reacciones de impotencia y de indefensión, por una parte; $y$, por otra, las reacciones agresivas basadas en la interpretación desproporcionada de una realidad neutra que se juzga como amenazante. 


\section{BiBLIOGRAFÍA}

ÁlVAREZ, M. (2001) Diseño y evaluación de programas de educación emocional. Barcelona, CISSPRAXIS.

BISQUERRA, R. (2002) Educación emocional y bienestar. Barcelona, CISSPRAXIS.

- (2003) Educación emocional y competencias básicas para la vida, Revista de Investigación Educativa, 21 (1), 7-43.

CoRbalán, F. (1998) Una vida enseñando matemáticas, Cuadernos de Pedagogía, 266, 72-75.

Díez, M. C. (1998) El oficio del maestro es aprender, Cuadernos de Pedagogía, 266, 58-61.

Esteve, J. M. (1994) El malestar docente. Barcelona, Paidós.

- (1997) La formación inicial de los profesores de secundaria. Barcelona, Ariel.

- (1998) El árbol del bien y del mal. Barcelona, Octaedro.

FeRnández CRUZ, M. (1995) Los ciclos vitales de los profesores. Granada, FORCE.

Ginnot, H. (1993) Teacher and Child. New York, Collier Books.

GÜELL, M. y MuÑo, J. (2003) Educación emocional. Barcelona, CISSPRAXIS.

Guil, A.; LOSCERTAles, F. y otros (1992) La interacción social en educación. Sevilla, SEDAL.

Hoffman, M. L. (2002) Desarrollo moral y empatía. Barcelona, Idea Books.

Huberman, M. (1989) La vie des enseignants. Neuchâtel, Delachaux et Niestlé.

Unamuno, M. (1917) Comentario, Boletín de la Institución Libre de Enseñanza.

VeENMAN, S. (1984) Perceived problems of beginning teachers, Review of Educational Research, $54(2), 143-178$.

VERA, J. (1988) El profesor principiante. Valencia, Promolibro.

VONK, J. H. C. (1983) Problems of the beginning teacher, European Journal of Teacher Education, 6 (2), 133-150. 